\title{
CARACTERÍSTICAS FÍSICO-gUIMICAS DE AMIDOS MODIFICADOS DE GRAU ALIMENTÍCIO COMERCIALIZADOS NO BRASIL ${ }^{1}$
}

\author{
Graziela de Oliveira da SILVA², Fabiano Franco TAKIZAWA ${ }^{2}$, Ricardo Alexandre PEDROSO ${ }^{3}$, \\ Célia Maria Landi FRANCO ${ }^{4}$, Magali LEONEL ${ }^{5}$, Silene Bruder Silveira SARMENTO ${ }^{6}$, Ivo Mottin DEMIATE ${ }^{7, *}$
}

\section{RESUMO}

Amidos nativos e modificados têm grande importância na indústria de alimentos, sendo empregados principalmente como espessantes e/ou estabilizantes. As limitações das pastas e géis obtidos a partir de amidos nativos tornaram necessário o desenvolvimento de muitos tipos de amidos modificados para aplicações alimentícias. Neste trabalho, algumas amostras de amidos modificados (n=20) disponíveis no Brasil foram recebidas de empresas produtoras e analisadas em relação a algumas características físico-químicas e propriedades tecnológicas. Um levantamento do uso de amidos modificados em alimentos também é apresentado, revelando crescente interesse pela indústria nesses ingredientes. Constatou-se que, enquanto alguns alimentos industrializados, como maioneses contêm em suas formulações amidos modificados, outros como condimento preparado de mostarda contêm apenas amido nativo. As análises físico-químicas permitiram concluir que alguns amidos modificados apresentavam teores elevados de acidez, relacionados à presença de reagentes utilizados em sua obtenção, não havendo presença de carboxilas nas suas macromoléculas. De maneira geral, os resultados de algumas propriedades tecnológicas avaliadas, tais como viscosidade aparente das pastas, resistência a congelamento/descongelamento e propriedade de expansão, estavam de acordo com a descrição dos produtos. As fontes mais observadas nas modificações foram, em ordem decrescente de importância, a mandioca, o milho ceroso e o milho regular.

Palavras-chave: mandioca, milho ceroso, alimentos, análise físico-química.

\section{SUMMARY}

PHYSICOCHEMICAL CHARACTERISTICS OF MODIFIED FOOD STARCHES COMMERCIALIZED IN BRAZIL. Native and modified starches are very valued for the food industry, being employed mainly as thickeners or stabilizers. Several technological limitations of native starch pastes or gels made it necessary to develop modified starches for the food industry. In the present work modified starch samples $(\mathrm{n}=20)$ available in Brazil were received from some producers and evaluated in relation to selected physicochemical characteristics and technological properties. Also a very simple evaluation of food starch market was done and allowed to conclude that Brazilian food industry is deeply interested on modified starches. It was possible to note that some foods like mayonnaise have on its composition modified starch whereas others like mustard sauce are produced only with native starch. The physicochemical analyses showed that some of the studied samples had high acidity levels, related with the presence of excess reagents employed on the starch modification processes; the results of carboxyl groups content allowed this conclusion. Almost all results were in agreement with the producers' specifications, for example for the freeze-thaw stability, apparent viscosity and the expansion power. The most frequent botanical sources among the studied samples were cassava, waxy corn and regular corn.

Keywords: cassava, waxy corn, food, physicochemical analyses.

\section{1 - INTRODUÇÃO}

O amido é a principal substância de reserva nas plantas superiores, fornecendo de 70 a $80 \%$ das calorias consumidas pelo homem. Os depósitos permanentes de amido

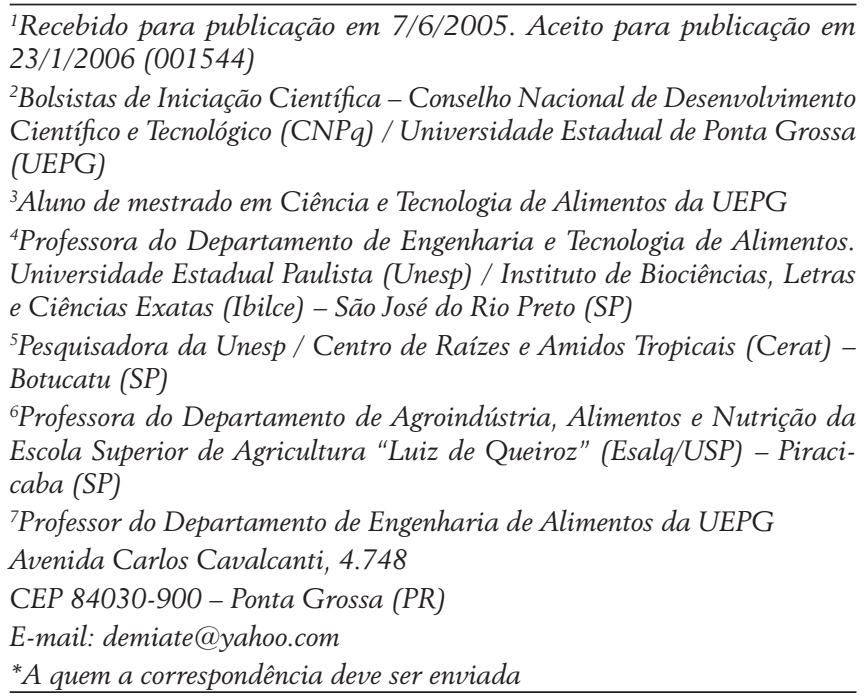

${ }^{1}$ Recebido para publicação em 7/6/2005. Aceito para publicação em 23/1/2006 (001544)

Bolsistas de Iniciação Científica - Conselho Nacional de Desenvolvimento Científico e Tecnológico (CNPq) / Universidade Estadual de Ponta Grossa (UEPG)

${ }^{3}$ Aluno de mestrado em Ciência e Tecnologia de Alimentos da UEPG

${ }^{4}$ Professora do Departamento de Engenharia e Tecnologia de Alimentos. Universidade Estadual Paulista (Unesp) / Instituto de Biociências, Letras e Ciências Exatas (Ibilce) - São José do Rio Preto (SP)

${ }^{5}$ Pesquisadora da Unesp / Centro de Raízes e Amidos Tropicais (Cerat) Botucatu (SP)

'Professora do Departamento de Agroindústria, Alimentos e Nutrição da Escola Superior de Agricultura "Luiz de Queiroz" (Esalq/USP) - Piracicaba (SP)

${ }^{7}$ Professor do Departamento de Engenharia de Alimentos da UEPG

Avenida Carlos Cavalcanti, 4.748

E-mail:demiate@yahoo.com

*A quem a correspondência deve ser enviada

nas plantas ocorrem tanto nos órgãos de reserva quanto em grãos de cereais (milho, arroz, trigo) e em tubérculos e raízes (batata, mandioca) [19].

O mercado de amidos vem crescendo e se aperfeiçoando nos últimos anos, levando à busca de produtos com características específicas que atendam às exigências da indústria. A produção de amidos modificados é uma alternativa que vem sendo desenvolvida há algum tempo com o objetivo de superar uma ou mais limitações dos amidos natives, e assim, aumentar a utilidade deste polímero nas aplicações industriais [20, 24].

As razões que levam à modificação, segundo BEMILLER [1], são: modificar as características de cozimento (gomificação); diminuir a retrogradação e a tendência das pastas em formarem géis; aumentar a estabilidade das pastas ao resfriamento e descongelamento, a transparência das pastas ou géis e a adesividade; melhorar a textura das pastas ou géis e a formação de filmes; e adicionar grupamentos hidrofóbicos e introduzir poder emulsificante.

Alterações nas propriedades tecnológicas dos amidos podem ser obtidas por processos físicos tais como tratamento térmico, exposição a radiações ou por processos 
químicos nos quais empregam-se reagentes específicos para alterar a estrutura das macromoléculas componentes do amido. Ainda há a possibilidade de serem empregados processos enzimáticos [1,14].

O emprego industrial de amido se deve à sua característica única de poder ser usado diretamente na forma de grânulos, de grânulos intumescidos, na forma dispersa, como filme obtido da secagem de uma dispersão ou após extrusão, depois da conversão a uma mistura de oligossacarídeos ou a glucose, que pode ser isomerizada enzimaticamente para frutose. Dependendo do tipo, o amido pode, entre outras funções, facilitar o processamento, servir como espessante em sopas, caldos e molhos de carne, fornecer sólidos em suspensão e textura, ser ligante em embutidos de carne, estabilizante em molhos de salada, ou ainda proteger os alimentos durante o processamento $[14,5]$.

Uma alta viscosidade é desejável para usos industriais, nos quais o objetivo é o poder espessante. Para isso, é necessário o controle da retrogradação no resfriamento. Uma das propriedades mais importantes do amido é a gomificação, que possibilita absorção, no aquecimento, de até 2,5 mil vezes seu peso em água. O aquecimento em excesso de água causa o intumescimento irreversível, porém limitado, dos grânulos, os quais se tornam muito sensíveis a estresses mecânico e térmico ou à acidez do meio. Mas, uma vez resfriado, ou ainda, congelado, os polímeros de amido nativo se reagrupam, liberando água e danificando o gel formado [2, 5].

As pastas de amidos de milho, trigo ou arroz, que contêm teores relativamente elevados de amilose se tornam opacas e formam géis durante o resfriamento. Pastas obtidas de féculas de batata ou de mandioca, por outro lado, geralmente permanecem mais claras (menos opacas) e, embora ao resfriarem apresentem um certo aumento de viscosidade, não chegam a formar géis opacos. No caso de pastas de amido de milho ceroso, as mesmas se comportam como as obtidas de féculas, tendo inclusive menor tendência à retrogradação [24].

O objetivo deste trabalho foi coletar amostras comerciais de amidos nativos e modificados disponíveis no mercado brasileiro, analisá-las para compreender algumas relações entre propriedades físico-químicas e tecnológicas e estabelecer associações com os usos na indústria de alimentos.

\section{2 - MATERIAL E MÉTODOS}

\section{1 - Material}

Amostras de amidos modificados $(n=20)$ foram obtidas de duas empresas produtoras para serem caracterizadas, tendo sido codificadas conforme mostrado na Tabela 1 . As amostras de amidos nativos que constam da Tabela 1 foram adquiridas no mercado local - Ponta Grossa (PR) -, tendo sido analisadas duas amostras de cada para os casos do milho regular e da mandioca.
TABELA 1 - Codificação das amostras de amidos

\begin{tabular}{|c|c|c|}
\hline $\begin{array}{l}\text { Amostras } \\
\text { codificadas }\end{array}$ & $\begin{array}{c}\text { Fonte } \\
\text { botânica }\end{array}$ & $\begin{array}{c}\text { Tipo de modificação } \\
\text { ou aplicação }\end{array}$ \\
\hline 1 & milho ceroso & intercruzado (a) \\
\hline 2 & milho ceroso & intercruzado/substituído (a) \\
\hline 3 & milho ceroso & intercruzado/substituído (b) \\
\hline 4 & milho ceroso & intercruzado/substituído (c) \\
\hline 5 & milho ceroso & intercruzado (b) \\
\hline 6 & milho ceroso & molho para salada \\
\hline 7 & milho ceroso & intercruzado (c) \\
\hline 8 & mandioca & intercruzado/substituído (a) \\
\hline 9 & mandioca & intercruzado/substituído (b) \\
\hline 10 & mandioca & pão de queijo (a) \\
\hline 11 & mandioca & pão de queijo (b) \\
\hline 12 & milho regular & ácido modificado (a) \\
\hline 13 & mandioca & dextrina \\
\hline 14 & mandioca & modificado pré-gel \\
\hline 15 & mandioca & resistente a ciclos congelamento \\
\hline 16 & mandioca & resistente à temperatura, acidez e agitação \\
\hline 17 & mandioca & modificado pré-gel (a) \\
\hline 18 & mandioca & modificado pré-gel (b) \\
\hline 19 & mandioca & nativo (a) \\
\hline 20 & milho regular & nativo (a) \\
\hline 21 & milho regular & ácido modificado (b) \\
\hline 22 & milho regular & ácido modificado (c) \\
\hline 23 & milho ceroso & nativo \\
\hline 24 & milho regular & nativo (b) \\
\hline 25 & mandioca & nativo (b) \\
\hline
\end{tabular}

(a), (b), (c) representam amostras com diferentes graus de modificação e/ou de diferentes produtores

\section{2 - Métodos}

Inicialmente, foi realizado um levantamento da utilização de amidos modificados em alimentos, a partir da elaboração e aplicação de questionários e pesquisa em supermercados. Também foram realizadas visitas a empresas do setor de amido.

As amostras comerciais de amidos modificados foram analisadas empregando-se a Espectroscopia na Região do Infravermelho Médio (FTIR) e metodologias convencionais, para verificação de algumas características físico-químicas e tecnológicas.

\subsection{1 - Espectroscopia FTIR dos amidos}

A análise das amostras foi realizada empregando-se um espectrofotômetro FTIR Nicolet Avatar 360, equipado com detector DTGS. A faixa espectral considerada foi 4.000 a $700 \mathrm{~cm}^{-1}$, com ênfase na região denominada "impressão digital", de 2.000 a $700 \mathrm{~cm}^{-1}$, que possibilita uma investigação da estrutura molecular dos compostos analisados $[9,10,11]$. A técnica mais comum para amostragem de pós é a preparação de pastilhas de $\mathrm{KBr}$ [15], que foi empregada nesse estudo. 
As pastilhas, de $13 \mathrm{~mm}$ de diâmetro, foram obtidas com $100 \mathrm{mg}$ de $\mathrm{KBr}$ seco e $2 \mathrm{mg}$ (base seca) de amostra em prensa hidráulica manual (carga de 10 ton). $\mathrm{O} \mathrm{KBr}$ puro é usado como referência para a coleta dos espectros das amostras [15]. O número de varreduras foi de 100, e utilizou-se a função de apodização triangular do software Nicolet para a obtenção dos espectros $[9,10]$.

\subsection{2 - Caracterização físico-química}

$\mathrm{Na}$ avaliação físico-química das amostras foram considerados: pH, propriedade de expansão, poder de inchamento e solubilidade dos grânulos, resistência a ciclos de congelamento e descongelamento e viscosidade aparente das pastas, empastamento, poder redutor, teor de carboxilas, acidez e ácidos orgânicos.

pH - Para determinação do pH, 20 g de amido foram dispersos em $100 \mathrm{~mL}$ de água deionizada e a suspensão agitada por 30 min. Cessada a agitação, mediu-se o pH imediatamente, em potenciômetro calibrado, à temperatura ambiente $\left(20^{\circ} \mathrm{C}\right)[22]$.

Propriedade de expansão - Na obtenção das massas para avaliação da propriedade de expansão, 12 g de amido foram parcialmente gomificados com $10 \mathrm{~mL}$ de água deionizada em ebulição. Após a homogeneização manual da fécula, a massa foi dividida em três esferas com tamanhos iguais, sendo levadas a um forno elétrico pré-aquecido a $200^{\circ} \mathrm{C}$ e assadas por $25 \mathrm{~min}$. Ao final desse período, após resfriarem, as esferas expandidas foram pesadas. As esferas foram impermeabilizadas com parafina fundida e seus volumes medidos pelo deslocamento de água em proveta graduada [7]. Esse método foi selecionado por apresentarse mais adequado ao produto a ser analisado, ainda que o deslocamento de sementes (alpiste, painço) seja o método mais comumente empregado. O deslocamento de sementes, entretanto, pode gerar resultados cuja reprodutibilidade é baixa [16]. O resultado da expansão foi expresso em volume específico, em mL/g [3, 4].

Poder de inchamento e solubilidade dos grânulos Foram determinados em diferentes temperaturas (50, 60, 70,80 e $90^{\circ} \mathrm{C}$ ), conforme descrito por LEACH et al. [18]. A análise é desenvolvida em tubos de centrífuga de $50 \mathrm{~mL}$. A determinação envolve a suspensão em $40 \mathrm{~mL}$ de água deionizada de uma massa de amostra (250 mg), que foi colocada em banho-maria nas temperaturas citadas, sendo mantida em suspensão por agitação mecânica. Após 30 min de tratamento térmico, os tubos foram levados à centrífuga $(2.200$ $\mathrm{rpm} / 10 \mathrm{~min}$.) para a separação de fases. O sobrenadante foi coletado e seco para a quantificação da fração solúvel e os tubos, contendo os grânulos de amido intumescidos, pesados. A solubilidade é expressa em porcentagem em peso enquanto o poder de inchamento em vezes de ganho de peso em relação à massa de amostra inicial.

Resistência a ciclos de congelamento e descongelamento - Pastas a 5\% foram armazenadas congeladas em embalagens plásticas herméticas e a quantidade de água liberada determinada gravimetricamente [6]. A quantidade de água liberada foi expressa como porcentagem de perda de peso da pasta inicial.

Viscosidade aparente das pastas - O perfil de viscosidade dos amidos foi determinado usando um rápido visco analisador (RVA) (modelo RVA-4, Newport Scientific, Austrália) [13, 21]. Uma suspensão de amido ( $9 \%$ p/p, bs; 28 g, peso total) foi misturada em recipiente de alumínio, equilibrada a $50^{\circ} \mathrm{C}$ por $1 \mathrm{~min}$, aquecida a $95^{\circ} \mathrm{C}$ numa taxa de $6^{\circ} \mathrm{C} / \mathrm{min}$, permanecendo nesta temperatura por $5 \mathrm{~min}$. Em seguida, a pasta foi resfriada a $50^{\circ} \mathrm{C}$, numa taxa de $6^{\circ} \mathrm{C} / \mathrm{min}$, e mantida nesta temperatura por $2 \mathrm{~min}$. A suspensão foi agitada a 160 rpm durante todo o experimento. As análises foram realizadas em duplicata. As propriedades de pasta dos amidos foram determinadas usando o software Thermocline for Windows, versão 2.2. Avaliou-se o perfil de cozimento das pastas pela observação da temperatura de empastamento, viscosidade máxima (pico), viscosidade mínima durante manutenção da temperatura a $95^{\circ} \mathrm{C}$, quebra (viscosidade máxima - viscosidade mínima durante a manutenção) e viscosidade final das pastas a $50^{\circ} \mathrm{C}$. Os resultados de viscosidade aparente foram expressos em unidades do rápido visco analisador (RVU).

Empastamento - Para o estudo do empastamento, foram feitas suspensões aquosas de amido $5 \%(\mathrm{p} / \mathrm{p})$, aquecidas e fotografadas em três momentos: no início, 5 e 10 min após o empastamento.

Poder redutor - O poder redutor foi determinado utilizando-se a redução de cianeto férrico para cianeto ferroso pelo amido, tendo como precipitado um composto com zinco. Os íons férricos em excesso reduzem I', e este iodo é então titulado com tiossulfato [17]. Certos carboidratos (em especial os açúcares redutores) têm uma grande tendência a perder elétrons, devido à presença do grupo carbonila, podendo ser determinada por meio da redução de sais metálicos em meio alcalino.

Teor de carboxilas - O teor de carboxilas foi encontrado suspendendo-se $500 \mathrm{mg}$ de amido em $30 \mathrm{~mL}$ de HCl. Após 30 min, essas amostras foram lavadas. Depois da adição de $300 \mathrm{~mL}$ de água, foram gomificadas durante $10 \mathrm{~min} \mathrm{e}$ tituladas com $\mathrm{NaOH} 0,002 \mathrm{~N}$.

Acidez - A acidez foi medida em uma suspensão de amido $10 \%$ em agitação por $30 \mathrm{~min}$. Após isto, o sobrenadante foi filtrado e titulado com $\mathrm{NaOH} 0,1 \mathrm{~N}$.

Ácidos orgânicos - A análise das amostras foi realizada empregando-se um cromatógrafo líquido de alta eficiência (CLAE) marca Varian modelo Pro Star 410, com a utilização de duas bombas binárias, e injetor automático (auto sampler 410). O cromatógrafo estava equipado com detector de índice de refração e coluna Bio-Rad HPX87H. As amostras foram centrifugadas a $12.000 \mathrm{rpm}$ durante 8 min e, em seguida, filtradas em membrana PVDF 0,22 $\mu \mathrm{m}$ de poro e $40 \mathrm{~mm}$ de diâmetro, hidrofílico marca Millipore em vácuo, com o auxílio de um holder e seringa de $1 \mathrm{~mL}$. Estas amostras foram então colocadas no injetor automático com um tempo de corrida de $35 \mathrm{~min}$. A fase móvel empregada foi ácido sulfúrico 0,005 M, com a temperatura da coluna de $65^{\circ} \mathrm{C}$ e um fluxo de $0,6 \mathrm{~mL}$ por min. 


\section{3 - RESULTADOS E DISCUSSÃO}

\section{1 - Levantamento da aplicação em alimentos de amidos modificados}

O levantamento elaborado a partir da aplicação de questionários e de visitas a empresas do setor de amidos revelou que a produção está concentrada em algumas companhias multinacionais que conseguem produzir, a partir de tecnologias disponíveis em suas matrizes no exterior, certa variedade de amidos modificados que tem mercado crescente no País.

Destacam-se os produtos para aplicação em indústria de papel e celulose, especialmente os amidos catiônicos. Uma área de grande interesse comercial é a de amidos para aplicação em alimentos. Neste caso, entretanto, há poucos produtores em função das exigências das empresas que utilizam os amidos. em quanto à higiene. Enquanto na produção de amidos industriais (papel e celulose, indústria química e têxtil) há empresas nacionais atuando - fecularias de mandioca -, no caso de amidos modificados para alimentos essa produção está limitada às companhias maiores, que conseguem atender aos padrões exigidos pela indústria alimentícia.

Há uma tendência muito grande de aumento da oferta de amidos modificados de grau alimentício, ainda pouco empregados no Brasil. Seguindo-se o que ocorreu nos países mais desenvolvidos, a indústria de alimentos nacional tem buscado novos ingredientes que possam melhorar a qualidade de seus produtos e diminuir custos de produção e/ou aumentar os lucros sem perda da qualidade sensorial.

Apesar de ter sido possível visitar e receber amostras e informações de algumas empresas, outras não permitiram visitas e se negaram a ceder amostras de produtos comerciais, para que fossem analisadas neste estudo. Existe um grande interesse comercial nesta área, com boas perspectivas para os usuários de amidos modificados. Uma outra informação relevante é a de que companhias multinacionais cultivam milho ceroso no Brasil exclusivamente para a produção de alguns tipos de amidos modificados. Elas estão muito interessadas no amido de mandioca, para a produção de modificados. Neste aspecto, é importante salientar a aquisição de algumas fecularias brasileiras por grandes companhias para a obtenção de matéria-prima para as modificações químicas.

Misturas de amidos de diferentes fontes, principalmente milho regular, milho ceroso e mandioca, também são feitas para se atingir as propriedades tecnológicas desejadas nas aplicações dos amidos modificados. Das 25 amostras consideradas neste estudo, recebidas de empresas processadoras de amido, 12 eram de mandioca, oito de milho ceroso e apenas cinco de milho regular, o que mostra a importância do amido de mandioca na obtenção de modificados de interesse comercial.

Um levantamento feito em supermercados revelou que a aplicação de amidos modificados vem crescendo rapidamente no Brasil. Apesar dessa expansão, ainda não se pode comparar com o que ocorre na indústria de alimentos de países europeus, onde a utilização dos amidos modificados acontece com maior freqüência e em muitos produtos [23]. No Brasil, ainda é comum encontrar produtos que utilizam amidos nativos, o que pode ser atribuído ao menor custom, apesar de algumas vezes haver problemas tecnológicos associados ao uso desses espessantes/estabilizantes.

Na Tabela 2, são mostradas algumas aplicações dos amidos em produtos alimentícios industrializados. Os dados desta Tabela foram obtidos durante os anos de 2003 e 2004, pela análise dos rótulos de alimentos comercializados em supermercados da região onde este estudo foi desenvolvido.

TABELA 2 - Utilização de amidos modificados em produtos alimentícios industrializados

\begin{tabular}{|c|c|c|c|c|}
\hline Tipo/Classe & $\begin{array}{c}\mathrm{N}^{\circ} \text { de } \\
\text { amostras }\end{array}$ & $\begin{array}{l}\text { Amido } \\
\text { nativo }\end{array}$ & $\begin{array}{l}\text { Amido } \\
\text { modificado }\end{array}$ & $\begin{array}{c}\text { Sem } \\
\text { amido } \\
\text { adicionado }\end{array}$ \\
\hline Maionese & 7 & 0 & 7 & 0 \\
\hline Molhos para salada & 3 & 0 & 3 & 0 \\
\hline $\begin{array}{l}\text { Condimento } \\
\text { preparado (mostarda) }\end{array}$ & 3 & 3 & 0 & 0 \\
\hline Molho de tomate & 9 & 2 & 7 & 0 \\
\hline Doces em pasta & 5 & 5 & 0 & 0 \\
\hline $\begin{array}{l}\text { Misturas para } \\
\text { sobremesa }\end{array}$ & 7 & 5 & 2 & 0 \\
\hline Sopas & 9 & 9 & 0 & 0 \\
\hline Biscoitos & 16 & 13 & 0 & 3 \\
\hline Balas e confeitos & 10 & 8 & 2 & 0 \\
\hline Pães & 9 & 7 & 0 & 2 \\
\hline Congelados & 21 & 5 & 16 & 0 \\
\hline Macarrão & 4 & 2 & 2 & 0 \\
\hline Sobremesas lácteas & 7 & 2 & 4 & 1 \\
\hline $\begin{array}{l}\text { logurtes e bebidas } \\
\text { lácteas }\end{array}$ & 11 & 8 & 3 & 0 \\
\hline $\begin{array}{l}\text { Requeijão cremoso } \\
\text { e produtos tipo } \\
\text { requeijão cremoso }\end{array}$ & 8 & 2 & 3 & 3 \\
\hline Alimentos infantis & 4 & 4 & 0 & 0 \\
\hline Embutidos & 25 & 23 & 1 & 1 \\
\hline TOTAL & 158 & 98 & 50 & 10 \\
\hline
\end{tabular}

Os dados apresentados na Tabela 2 revelam que em certos tipos de alimentos, como maionese e molhos para saladas, há adição de amidos modificados em todas as marcas comercializadas. É importante salientar que, de maneira geral, a indústria busca padrões de qualidade sensorial nos produtos líderes de mercado, e isso faz com que haja tendência de uma homogeneidade dos ingredientes e aditivos empregados na fabricação.

A utilização dos amidos modificados em maionese possibilita considerável redução do teor lipídico (cerca de $50 \%$ ), e os fabricantes indicam na rotulagem o termo "reduzido teor de gordura". Isto é interessante neste tipo de alimento conhecido por ser excessivamente calórico, 
mas muito apreciado pelos consumidores. Em relação ao valor calórico, consegue-se, segundo informação da rotulagem de uma marca de maionese disponível no mercado, $47 \%$ de redução.

Considerando-se o custo dos amidos modificados, pode-se perceber que, de maneira geral, produtos mais sofisticados e caros levam esses amidos e, em contrapartida, produtos mais populares têm, em suas formulações, amidos nativos. É o caso dos embutidos, nos quais apenas uma amostra encontrada tem em sua formulação amido modificado. Em produtos como requeijão cremoso, só três amostras das oito encontradas não continham amido. Das cinco amostras com amido, duas tinham amido nativo e três, amido modificado na constituição. Dessa forma, o produto contendo amido é denominado "especialidade láctea com requeijão cremoso", constando essa informação no rótulo, ainda que o termo "especialidade láctea" esteja em letras miúdas e "requeijão cremoso", com grande destaque. Assim, o consumidor menos atento acaba não percebendo que está diante de produtos diferentes e que deveriam ter preços também distintos. As indústrias, preocupadas em aumentar os lucros, desenvolvem novos produtos, por vezes menos nutritivos, mas com características sensoriais favoráveis à comercialização.

É importante destacar que na rotulagem dos alimentos a denominação "amido modificado" cabe apenas aos amidos que foram submetidos a tratamentos químicos. No caso dos amidos pré-gelatinizados, que são submetidos apenas a processos físicos (tratamento térmico), aparecem como "amido" na listagem de ingredientes.

\section{2 - Espectroscopia FTIR dos amidos}

A análise das amostras comerciais de amidos modificados foi realizada com a coleta dos espectros na região do infravermelho médio. Na Figura 1, os espectros são apresentados considerando-se a região de 4.000 a $400 \mathrm{~cm}^{1}$, e na Figura 2, são mostrados os espectros da região de $2.000-1.500 \mathrm{~cm}^{-1}$, que revela a presença de grupamentos carbonila em algumas amostras.

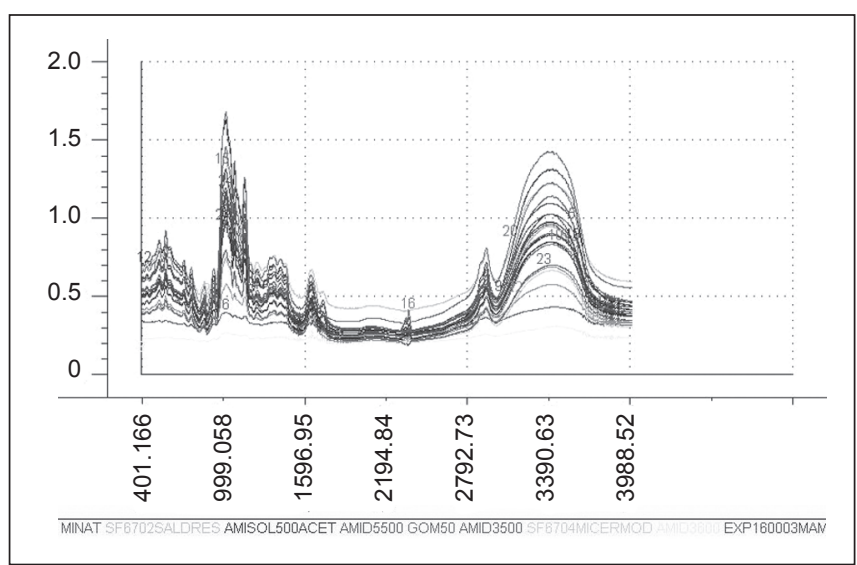

FIGURA 1 - Espectros na região do infravermelho médio (4.000$400 \mathrm{~cm}^{-1}$ ) das amostras comerciais de amidos modificados

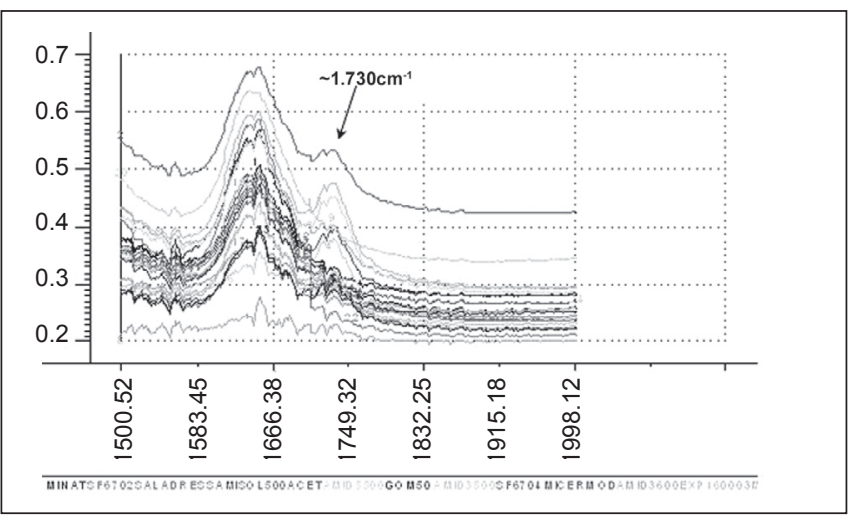

FIGURA 2 - Espectros região do infravermelho médio (2.000-1.500 $\mathrm{cm}^{-1}$ ) das amostras comerciais de amidos modificados

Conforme mostrado na Figura 2, houve um pico na região próxima a $1.730 \mathrm{~cm}^{-1}$, o que pode ser atribuído à presença de grupamentos carbonila [12], que não existem no amido nativo. Esse resultado, já obtido em outros trabalhos, poderia representar a presença, por exemplo, de grupamentos carboxila ácidos em amostras de amidos oxidados [8]. A presença de reagentes ou de compostos de degradação, resultantes do tratamento químico do amido, também pode estar associada ao aparecimento da absorção nessa região do espectro. Observando-se os resultados do teor de carboxilas e da acidez das amostras, é possível afirmar que o pico mostrado na Figura 2 está associado à presença de reagentes ou subprodutos das reações químicas que ocorrem durante a produção de alguns dos amidos modificados estudados.

\section{3 - Caracterização físico-química}

Os resultados da caracterização físico-química referemse ao $\mathrm{pH}$, propriedade de expansão, poder de inchamento e solubilidade dos grânulos, claridade, resistência a ciclos de congelamento e descongelamento e viscosidade aparente das pastas, empastamento, poder redutor, teor de carboxilas, acidez e ácidos orgânicos.

\subsection{1 - pH}

Os valores de $\mathrm{pH}$ das amostras variaram de 3,4 a 6,3. A amostra que apresentou o menor $\mathrm{pH}$, de 3,4, era uma dextrina, indicando que não houve lavagem ou neutralização completa para retirada dos resíduos do ácido utilizado para a modificação. Essa constatação de que o pH final das amostras varia bastante certamente interfere na aplicação final dos amidos modificados, podendo ser benéfica, mas em alguns casos indesejável. É interessante para quem utiliza os amidos modificados, conhecer o $\mathrm{pH}$ do produto para avaliar as implicações desta característica na utilização do material.

No caso das amostras de amidos intercruzados/substituídos, o pH variou de 4,4 a 5,5, enquanto para as amostras apenas intercruzadas os valores variaram de 4,8 a 5,3. Nas amostras modificadas por ácido, o $\mathrm{pH}$ variou de 5,2 a 5,5. Os amidos nativos analisados, de milho regular, mandioca e milho ceroso apresentaram pHs 5,0, 5,6 e 5,0, respectivamente. 


\subsection{2 - Propriedade de expansão}

As amostras 10 e 11 apresentaram valores de expansão de 13,1 e 7,5 mL/g, respectivamente. Essas duas amostras são descritas pelo fornecedor como apropriadas para a produção de pão de queijo, sendo esperado que apresentassem valores elevados de expansão. Dessa forma, o resultado mostra-se condizente com a indicação do fornecedor. Além desses amidos modificados para a formulação de pão de queijo, apenas duas outras amostras tiveram valores relativamente elevados de expansão, a 18 e a 23, mandioca pré-gelatinizada modificada e milho ceroso nativo, respectivamente. $\mathrm{O}$ amido de milho ceroso nativo apresentou valor superior ao da amostra 11, que é modificada para apresentar a propriedade de expansão. Assim, considerando-se apenas a capacidade de expansão, o amido de milho ceroso nativo poderia também ser utilizado na aplicação sugerida para as amostras 10 e 11, sem necessidade de proceder qualquer modificação química em seus grânulos.

\subsection{3 - Poder de inchamento e solubilidade dos grânulos}

Na Tabela 3, são apresentados os valores de poder de inchamento e solubilidade dos grânulos dos amidos. Pode-se observar que à temperatura de $90^{\circ} \mathrm{C}$ foram obtidos os maiores valores de poder de inchamento, quando grande parte dos grânulos está intumescida. Considerando-se, entretanto, que

TABELA 3 - Valores de poder de inchamento e solubilidade das amostras às temperaturas de $50,70,80 \mathrm{e} 90^{\circ} \mathrm{C}$ (expressos em vezes de aumento de peso e \% p/p, respectivamente)

\begin{tabular}{|c|c|c|c|c|c|c|c|c|}
\hline Amostra & Por & er de i & nchame & ento & & Solubi & lidade & \\
\hline & $50^{\circ} \mathrm{C}$ & $70^{\circ} \mathrm{C}$ & $80^{\circ} \mathrm{C}$ & $90^{\circ} \mathrm{C}$ & $50^{\circ} \mathrm{C}$ & $70^{\circ} \mathrm{C}$ & $80^{\circ} \mathrm{C}$ & $90^{\circ} \mathrm{C}$ \\
\hline 1 & 2,1 & 14,1 & 15,9 & 14,7 & 1,7 & 5,0 & 2,4 & 9,4 \\
\hline 2 & 4,2 & 17,7 & 22,2 & 15,9 & 1,3 & 11,6 & 6,4 & 8,9 \\
\hline 3 & 3,3 & 14,2 & 19,6 & 15,8 & 1,5 & 6,4 & 5,6 & 7,8 \\
\hline 4 & 2,9 & 15,8 & 17,8 & 15,2 & 2,3 & 8,5 & 5,2 & 19,1 \\
\hline 5 & 2,0 & 13,9 & 16,9 & 14,7 & 0,3 & 3,8 & 6,1 & 27,1 \\
\hline 6 & 3,4 & 16,3 & 14,9 & 12,5 & 8,9 & 11,1 & 4,2 & 15,2 \\
\hline 7 & 2,8 & 15,6 & 18,3 & 17,3 & 1,1 & 12,7 & 17,2 & 9,5 \\
\hline 8 & 2,8 & 12,8 & 13,7 & 17,0 & 0,5 & 12,4 & 14,5 & 16 \\
\hline 9 & 6,6 & 15,4 & 18,6 & 18,0 & 4,1 & 23,1 & 21,6 & 19,6 \\
\hline 10 & 3,5 & 22,1 & 30,9 & $160^{*}$ & 2,6 & 50,8 & 50,1 & $100,0^{*}$ \\
\hline 11 & 3,9 & 23,9 & 27,4 & $160^{*}$ & 1,8 & 27,2 & 42,7 & $100,0^{*}$ \\
\hline 12 & 4,3 & 8,2 & 6,8 & 9,2 & 0,8 & 34,8 & 23,4 & 62,4 \\
\hline 13 & 17,7 & 0,0 & 0,0 & 0,0 & 40,7 & $100,0^{*}$ & $100,0^{*}$ & $100,0^{*}$ \\
\hline 14 & 10,7 & 11,6 & 13,2 & 13,5 & 11,3 & 12,3 & 16,5 & 16,5 \\
\hline 15 & 6,1 & 12,9 & 13,5 & 13,9 & 3,6 & 6,3 & 5,6 & 7 \\
\hline 16 & 5,3 & 21,1 & 32,8 & 23,9 & 2,8 & 16,0 & 14,8 & 2,5 \\
\hline 17 & 11,4 & 20,8 & 12,6 & $160,0^{*}$ & 15,9 & 23,6 & 31,2 & $100,0^{*}$ \\
\hline 18 & 40,0 & 48,6 & $160,0^{*}$ & $160,0^{*}$ & $100,0^{*}$ & $100,0^{*}$ & $100,0^{*}$ & $100,0^{*}$ \\
\hline 19 & 3,2 & 19,8 & 22,4 & $160,0^{*}$ & 0,6 & 27,5 & 80,6 & $100,0^{*}$ \\
\hline 20 & 1,8 & 12,4 & 11,0 & 14,5 & 0,5 & 10,6 & 10,7 & 19,7 \\
\hline 21 & 2,5 & 3,1 & 4,9 & 16 & 3,5 & 48,0 & 72,4 & 70,0 \\
\hline 22 & 2,0 & 8,8 & 10,5 & 6,6 & 0,9 & 26,6 & 41,2 & 58,6 \\
\hline 23 & 2,7 & 25,2 & $160,0^{*}$ & $160,0^{*}$ & 0,3 & 26,7 & $100,0^{*}$ & $100,0^{*}$ \\
\hline 24 & 1,8 & 12,4 & 11,0 & 14,5 & 0,5 & 10,6 & 10,7 & 19,7 \\
\hline 25 & 2,4 & 24,3 & 25,6 & $160^{*}$ & 0,5 & 17,6 & 33,6 & $100,0^{*}$ \\
\hline
\end{tabular}

muitos amidos estudados eram intercruzados, percebe-se um inchamento limitado mesmo nesta temperatura, o que foi observado para as amostras 1 a 9 e também para a 15 e a 16 . Esta última amostra apresenta este comportamento na maior temperatura, quando comparada ao amido nativo de mandioca (19 e 25). Em relação ao inchamento limitado de outras amostras, deve-se ressaltar que se trata de amido de milho regular, nativo (20 e 24) e de ácido-modificado (12, 21 e 22).

Os resultados também mostram a solubilidade das dextrinas e amidos modificados pré-gelatinizados em todas as temperaturas, inclusive a $50^{\circ} \mathrm{C}$. Em algumas outras amostras não foi possível quantificar o poder de inchamento e a solubilidade pela metodologia utilizada, pois não ocorreu separação das fases, o que indica que ou o poder de inchamento foi máximo ( 160 vezes) ou a solubilidade foi de $100 \%$.

\subsection{4 - Resistência a ciclos de congelamento e descongelamento}

A análise de resistência a ciclos de congelamento/descongelamento é importante para caracterizar um tipo de amido em termos de sua aplicabilidade em alimentos que devem ser refrigerados e/ou congelados, visto que a liberação de água é geralmente prejudicial à qualidade do produto final. Pode-se notar, na Tabela 4, que algumas amostras (2, 4, 8, 9, 10,15 e 16) foram resistentes aos três ciclos de congelamen-

TABELA 4 - Valores obtidos para a resistência a ciclos de congelamento/descongelamento

\begin{tabular}{|c|c|c|c|}
\hline \multirow{2}{*}{ Amostra } & \multicolumn{3}{|c|}{ \% de água liberada } \\
\hline & $1^{\circ}$ Ciclo & $2^{\circ}$ Ciclo & $3^{\circ}$ Ciclo \\
\hline 1 & 27,80 & 45,44 & 42,44 \\
\hline 2 & 0,00 & 0,00 & 0,00 \\
\hline 3 & 0,00 & 0,00 & 23,84 \\
\hline 4 & 0,00 & 0,00 & 0,00 \\
\hline 5 & 0,00 & 45,02 & 43,42 \\
\hline 6 & 0,00 & 31,78 & 31,30 \\
\hline 7 & 37,28 & 30,12 & 35,24 \\
\hline 8 & 0,00 & 0,00 & 0,00 \\
\hline 9 & 0,00 & 0,00 & 0,00 \\
\hline 10 & 0,00 & 0,00 & 0,00 \\
\hline 11 & 0,00 & 0,00 & 6,00 \\
\hline 12 & 67,94 & 61,36 & 65,70 \\
\hline 13 & - & - & - \\
\hline 14 & 28,18 & 25,28 & 33,18 \\
\hline 15 & 0,00 & 0,00 & 0,00 \\
\hline 16 & 0,00 & 0,00 & 0,00 \\
\hline 17 & 0,00 & 0,00 & 5,60 \\
\hline 18 & 0,00 & 29,26 & 36,40 \\
\hline 19 & 0,00 & 7,56 & 19,44 \\
\hline 20 & 63,22 & 71,62 & 63,24 \\
\hline 21 & 64,56 & 69,16 & 70,00 \\
\hline 22 & 60,18 & 72,82 & 66,24 \\
\hline 23 & 0,00 & 20,04 & 59,12 \\
\hline 24 & 66,00 & 68,48 & 72,18 \\
\hline 25 & 0,00 & 29,52 & 24,04 \\
\hline
\end{tabular}


to/descongelamento. Duas dessas amostras eram de amido de milho ceroso (2 e 4) e cinco de mandioca $(8,9,10,15 \mathrm{e}$ 16). A amostra 15 é descrita pelo fornecedor como resistente a ciclos de congelamento/descongelamento, o que pôde ser comprovado. A amostra 16 é descrita pelo fornecedor como resistente à temperatura, acidez e agitação.

Conforme mostram os resultados, amidos nativos de mandioca e de milho ceroso são mais resistentes a ciclos de congelamento/descongelamento que o de milho regular, sendo esta uma importante característica para aplicações tecnológicas na indústria de alimentos.

De todas as amostras analisadas aquelas intercruzadas e substituídas foram as mais resistentes aos ciclos de congelamento/descongelamento, como era esperado. Destacaram-se também os amidos de mandioca modificados para a aplicação na produção de pão de queijo. As amostras de amidos apenas intercruzados (1, 5 e 7) mostraram susceptibilidade aos ciclos de congelamento/ descongelamento, com grande liberação de água das pastas.

\subsection{5 - Viscosidade aparente das pastas}

A partir da análise dos gráficos gerados na análise de viscosidade aparente das pastas, foram obtidos os valores de pico de viscosidade, manutenção (hold), quebra, viscosidade final e temperatura de empastamento, que são apresentados na Tabela 5. Observa-se que há grande diferença entre as amostras, o que já era esperado, visto que as modificações têm grande influência na viscosidade das pastas de amidos. A maior viscosidade final foi obtida para a amostra 16, que é apresentada como resistente à temperatura, acidez e agitação. O menor valor de viscosidade final foi obtido para a amostra 12, que é um amido de milho ácido modificado.

Os amidos modificados por tratamento ácido apresentam uma diminuição expressiva na viscosidade, o que foi comprovado para essa amostra. Amidos pré-gelatinizados (amostras 14, 17 e 18) e dextrinas (amostra 13) não foram avaliados em relação à viscosidade aparente de suas pastas. No caso das amostras 15 e 22, os viscoamilogramas não são mostrados por problemas com a preparação do material para análise.

Nas Figuras 3, 4 e 5, são apresentados os perfis de cozimento de amostras de amidos de mandioca, milho ceroso e milho regular modificados por diferentes métodos, demonstrando a marcante diferença entre o intercruzamento juntamente com a adição de grupos substituintes e a conversão ácida. Analisando a viscosidade final podese observar que os amidos intercruzados, substituídos e intercruzados-substituídos apresentam alta viscosidade final, sendo mais resistentes e estáveis ao cozimento sob agitação; a variação nos valores da viscosidade final destes amidos é devido a diferentes intensidades de tratamento químico e também às fontes botânicas consideradas.

Os amidos ácido-modificados apresentam viscosidade final muito baixa (em torno de 17 RVU), permitindo a adição

TABELA 5 - Pico de viscosidade, viscosidade mínima na manutenção de temperatura a $95^{\circ} \mathrm{C}$, quebra, viscosidade final e temperatura de empastamento (T.E.) das amostras

\begin{tabular}{|c|c|c|c|c|c|}
\hline Amostra & $\begin{array}{l}\text { Pico de } \\
\text { viscosidade } \\
\left(\mathrm{RVU}^{\star}\right)\end{array}$ & $\begin{array}{c}\text { Viscosidade } \\
\text { mínima na manutenção } \\
\text { (RVU) }\end{array}$ & $\begin{array}{l}\text { Quebra** } \\
\text { (RVU) }\end{array}$ & $\begin{array}{l}\text { Viscosidade final } \\
\text { (RVU) }\end{array}$ & $\begin{array}{c}\text { Temperatura } \\
\text { empastamento }\left({ }^{\circ} \mathrm{C}\right)\end{array}$ \\
\hline 1 & 526,8 & 365,3 & 161,5 & 519,6 & 72,8 \\
\hline 2 & 561,5 & 354,0 & 207,5 & 529,4 & 69,3 \\
\hline 3 & 516,3 & 338,8 & 177,5 & 541,3 & 68,8 \\
\hline 4 & 529,9 & 315,4 & 214,5 & 460,2 & 68,4 \\
\hline 5 & 480,2 & 325,9 & 154,3 & 459,0 & 72,4 \\
\hline 6 & 382,2 & 314,2 & 68,0 & 517,5 & 70,5 \\
\hline 7 & 538,2 & 327,0 & 211,2 & 472,9 & 67,7 \\
\hline 8 & 316,2 & 233,7 & 82,5 & 439,8 & 69,2 \\
\hline 9 & 304,5 & 157,7 & 146,8 & 284,9 & 63,2 \\
\hline 10 & 198,8 & 70,8 & 128,0 & 95,8 & 63,3 \\
\hline 11 & 314,0 & 113,7 & 200,3 & 169,3 & 63,6 \\
\hline 12 & 49,0 & 8,9 & 40,1 & 15,8 & 76,0 \\
\hline 13 & n.a. & n.a. & n.a. & n.a. & n.a. \\
\hline 14 & n.a. & n.a. & n.a. & n.a. & n.a. \\
\hline 15 & n.a. & n.a. & n.a. & n.a. & n.a. \\
\hline 16 & 484,7 & 400,0 & 84,7 & 751,2 & 64,0 \\
\hline 17 & n.a. & n.a & n.a & n.a. & n.a. \\
\hline 18 & n.a. & n.a & n.a & n.a. & n.a. \\
\hline 19 & 436,8 & 117,7 & 319,1 & 191,3 & 63,2 \\
\hline 20 & 207,9 & 123,5 & 84,4 & 220,6 & 83,4 \\
\hline 21 & 49,2 & 8,6 & 40,6 & 18,2 & 74,4 \\
\hline 22 & n.a. & n.a. & n.a. & n.a. & n.a. \\
\hline 23 & 295,3 & 103,0 & 192,3 & 121,8 & 74,0 \\
\hline 24 & 216,1 & 126,4 & 89,7 & 225,5 & 74,4 \\
\hline 25 & 387,8 & 137,3 & 250,5 & 200,3 & 64,5 \\
\hline
\end{tabular}




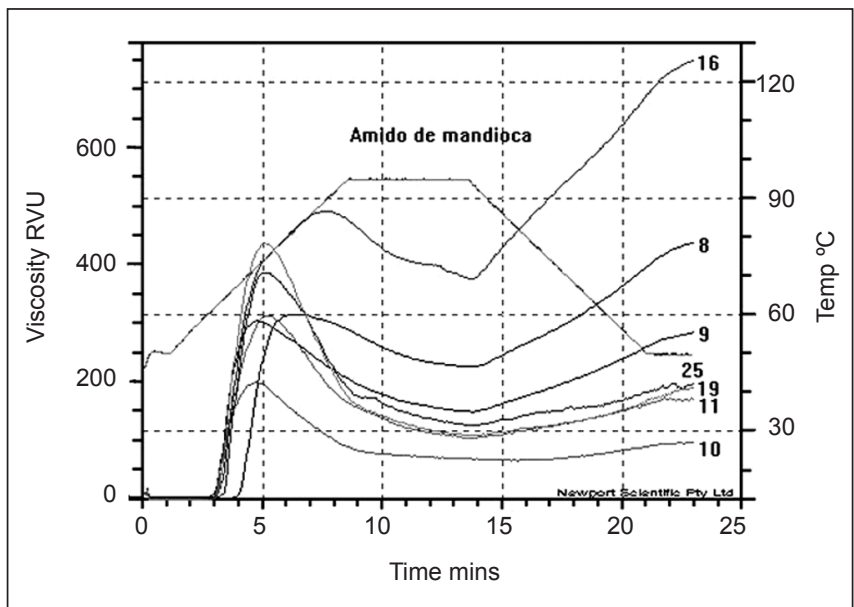

FIGURA 3 - Viscoamilogramas de amidos de mandioca nativos

(19 e 25) e modificados $(8,9,10,11,16)$

Consulte a Tabela

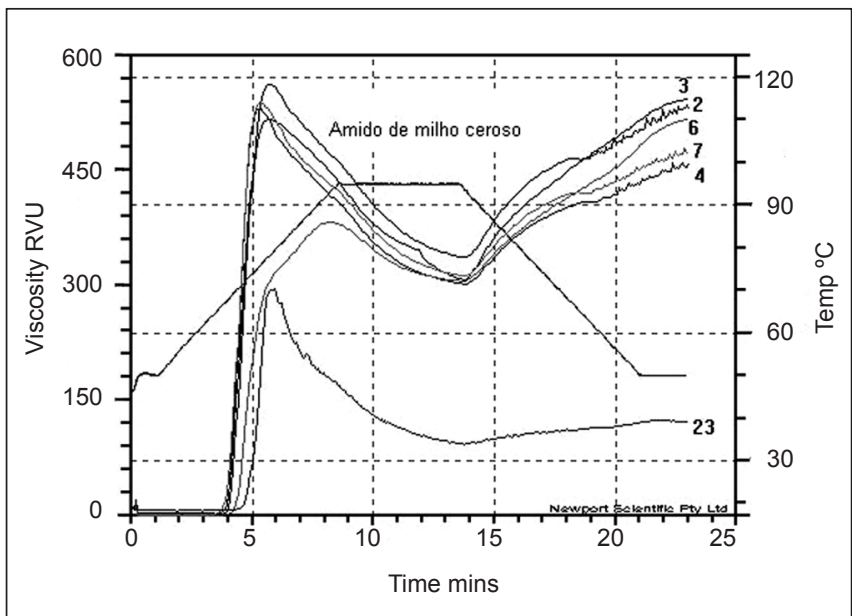

FIGURA 4 - Viscoamilogramas de amidos de milho ceroso nativo

(23) e modificados $(2,3,4,6,7)$

Consulte a Tabela 1

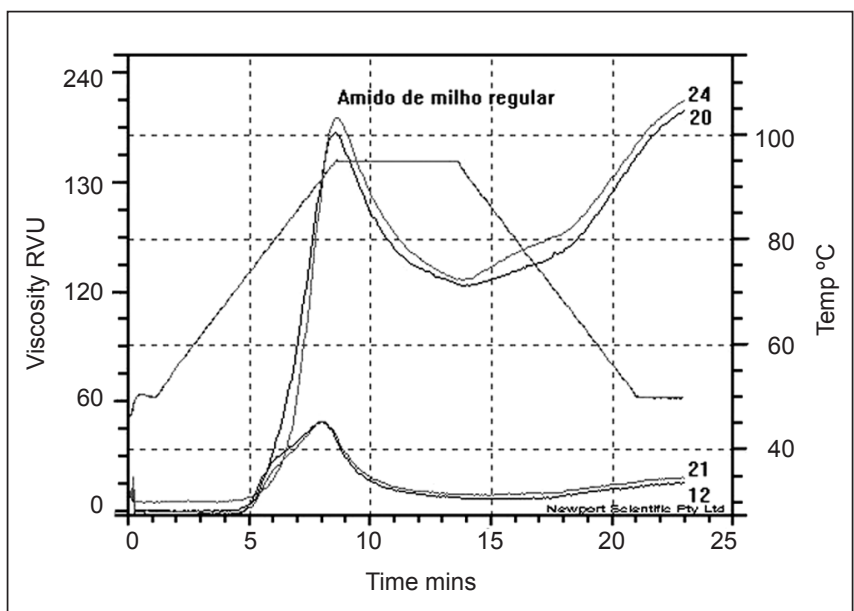

FIGURA 5 - Viscoamilogramas de amidos de milho regular nativos

$(20,24)$ e modificados $(12,21)$

Consulte a Tabela 1 de maior quantidade destes sem aumentar excessivamente a consistência final dos produtos.

Pode-se observar que os picos de viscosidade dos amidos podem aumentar ou diminuir de acordo com a modificação aplicada. O amido de milho ceroso intercruzado e substituído (amostra 2) apresentou o maior pico de viscosidade (561,5 RVU) e o amido de milho ácido-modificado (amostra 12) teve o menor pico de viscosidade ( 49 RVU). Esses resultados demonstram que o intercruzamento torna o amido mais resistente, e quando utilizado em conjunto com a adição de grupos lipofílicos a resistência é intensificada; por outro lado, a conversão por hidrólise ácida diminui consideravelmente a viscosidade das pastas, sendo os amidos modificados por esse tratamento denominados thin-boiling.

Considerando-se as temperaturas de empastamento dos amidos nativos de mandioca, milho e milho ceroso que estão em torno de 65,80 e $73^{\circ} \mathrm{C}$, respectivamente, pode-se dizer que do ponto de vista energético o amido de mandioca é o mais interessante, já que produz pasta viscosa mais rapidamente.

O amido de milho, embora tenha uma alta temperatura de empastamento, é muito utilizado em preparações de molhos ou sopas que precisam ser cozidos por 5 a 10 min, pois seus grânulos intumescem lentamente e apresentam viscosidade mais estável a quente que o amido de mandioca.

\subsection{6 - Empastamento}

A análise de empastamento foi realizada a fim de observar a influência do tempo de cozimento sobre a consistência e claridade das pastas. Pode-se observer nas fotografias apresentadas na Figura 6, a diferença na aparência das pastas, ocorrendo maior claridade (transparência) conforme aumenta o tempo de cozimento. Isso pode ser explicado, pois quanto maior o tempo de cozimento, maior o número de grânulos de amido que se intumescem e perdem a birrefringência, permitindo a passagem de luz.

A amostra 3 é um amido de milho ceroso intercruzado e substituído. Observa-se, na Figura 6, que as pastas parecem apenas parcialmente cozidas, mesmo após 10 min do empastamento ter iniciado. Ao compararmos as amostras 10, $14 \mathrm{e}$

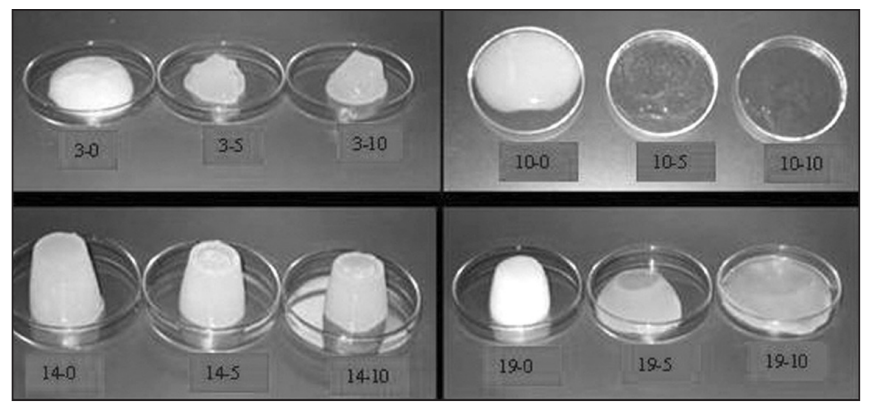

FIGURA 6 - Pastas obtidas das amostras 3, 10, 14 e 19, respectivamente, em três momentos, no início (0), 5 e 10 min após o empastamento

Consulte a Tabela 1 
19, todas de amido de mandioca, observa-se que a amostra 10 (amido modificado para fabricação de pão de queijo) parece ser mais instável ao cozimento, pois após 5 e 10 min do empastamento a pasta apresenta-se mais fluida e transparente.

Da mesma forma, no momento inicial do empastamento a amostra 10 apresenta-se mais fluida que a 19. A amostra 14, por sua vez, apesar de ser amido de mandioca, devido à modificação química, mostrou-se estável ao cozimento. É importante destacar também que esta amostra além de modificada é pré-gelatinizada, o que certamente contribuiu para que não houvesse comportamento muito diferente da pasta no início do empastamento e após 5 e 10 min de cozimento.

\subsection{7 - Poder redutor}

Na Tabela 6, são apresentados os valores de poder redutor encontrados para as amostras. No caso dos amidos ácido-modificados (todos amido de milho regular), os valores de poder redutor ficaram entre os mais elevados (amostras 12, 21 e 22). Segundo as informações do fabricante, a amostra 21 é um amido modificado com tratamento ácido com fluidez bem mais elevada que a da 22. A amostra 23, que apresentou elevado poder redutor em relação às outras, é o amido de milho ceroso nativo.

No caso da amostra 13, o valor de poder redutor foi elevado por tratar-se de uma dextrina.

TABELA 6 - Poder redutor ( $\mathrm{PR}, \mathrm{mg} \mathrm{Cu} / \mathrm{g}$ amido em base seca) das amostras de amidos

\begin{tabular}{lccc}
\hline Amostra & PR $(\mathbf{m g C u} / \mathbf{g})$ & Amostra & PR $(\mathbf{m g C u} / \mathbf{g})$ \\
\hline $\mathbf{1}$ & 0 & $\mathbf{1 3}$ & 116,21 \\
$\mathbf{2}$ & 0 & $\mathbf{1 4}$ & 0 \\
$\mathbf{3}$ & 1,44 & $\mathbf{1 5}$ & 0 \\
$\mathbf{4}$ & 0 & $\mathbf{1 6}$ & 0 \\
$\mathbf{5}$ & 2,89 & $\mathbf{1 7}$ & 2,74 \\
$\mathbf{6}$ & 0 & $\mathbf{1 9}$ & 1,42 \\
$\mathbf{7}$ & 0 & $\mathbf{2 0}$ & 1,43 \\
$\mathbf{8}$ & 0 & $\mathbf{2 1}$ & 22,43 \\
$\mathbf{9}$ & 0 & $\mathbf{2 2}$ & 2,80 \\
$\mathbf{1 0}$ & 1,44 & $\mathbf{2 3}$ & 8,45 \\
$\mathbf{1 1}$ & 0 & $\mathbf{2 4}$ & 2,93 \\
$\mathbf{1 2}$ & 5,84 & $\mathbf{2 5}$ & 2,68 \\
\hline
\end{tabular}

\subsection{8 - Acidez, teor de carboxilas e de ácidos orgânicos}

Os valores de acidez, carboxilas e ácidos orgânicos são apresentados na Tabela 7 .

Houve algumas variações no conteúdo de carboxila das amostras, entretanto não foram relacionados a outros resultados deste estudo. Comparando-se com os resultados de acidez e teor de ácidos orgânicos, foi possível concluir se havia contaminantes solúveis nas amostras e se foram eliminados durante a análise de carboxilas.
TABELA 7 - Acidez, teores de carboxilas e de ácidos orgânicos das amostras

\begin{tabular}{|c|c|c|c|}
\hline Amostra & $\begin{array}{c}\text { Acidez } \\
\text { (mL NaOH N/ } \\
100 \mathrm{~g} \mathrm{amido})\end{array}$ & $\% \mathrm{COOH}$ & $\begin{array}{c}\text { Ácidos } \\
\text { orgânicos } \\
\text { (g/kg, b.s.) }\end{array}$ \\
\hline 1 & 1,19 & 0,22 & 0,26 \\
\hline 2 & 8,51 & 0,27 & 0,59 \\
\hline 3 & 13,86 & 0,33 & 1,47 \\
\hline 4 & 14,85 & 0,21 & 1,82 \\
\hline 5 & 0,99 & 0,23 & 0,09 \\
\hline 6 & 5,74 & 0,18 & 0,67 \\
\hline 7 & 19,34 & 0,20 & 4,12 \\
\hline 8 & 1,19 & 0,24 & 0,18 \\
\hline 9 & 7,96 & 0,16 & 1,19 \\
\hline 10 & 6,14 & 0,30 & 0,53 \\
\hline 11 & 7,72 & 0,29 & 2,09 \\
\hline 12 & 0,79 & 0,20 & 0,05 \\
\hline 13 & n.a. & n.a. & n.a. \\
\hline 14 & n.a. & n.a. & n.a. \\
\hline 15 & 9,11 & 0,23 & 1,08 \\
\hline 16 & 14,26 & 0,35 & 2,86 \\
\hline 17 & n.a. & n.a. & n.a. \\
\hline 18 & n.a. & n.a. & n.a. \\
\hline 19 & 1,39 & 0,30 & 0,26 \\
\hline 20 & 1,39 & 0,26 & 0,09 \\
\hline 21 & 1,19 & 0,25 & 0,16 \\
\hline 22 & 1,19 & 0,22 & 0,04 \\
\hline 23 & n.a. & 0,16 & n.a. \\
\hline 24 & n.a. & 0,23 & n.a. \\
\hline 25 & n.a. & 0,16 & n.a. \\
\hline
\end{tabular}

Os resultados de acidez das amostras são coerentes com os espectros FTIR, sendo que as amostras com maiores valores de acidez apresentaram picos na região próxima a $1.730 \mathrm{~cm}^{-1}$. A correlação entre essas análises mostrou-se alta, permitindo concluir que há influência de ácidos orgânicos presentes nas amostras, gerados durante as reações de modificação dos amidos.

Houve presença considerável de ácidos orgânicos nestas amostras comerciais, que provavelmente são ácidos residuais decorrentes da modificação ou formados devido à degradação parcial das macromoléculas constituintes do amido. Considerando-se os padrões empregados na análise dos ácidos orgânicos por CLAE, o ácido encontrado em maior concentração na maior parte das amostras foi o acético. Comparando-se os valores determinados por CLAE com a acidez obtida por titulação, foi possível verificar que eles estão relacionados, conforme ilustrado pela Figura 7 .

\section{4 - CONCLUSÕES}

O desenvolvimento deste trabalho possibilitou conhecer algumas peculiaridades dos amidos modificados disponíveis no Brasil, assim como a forma como esses ingredientes são produzidos. Houve dificuldade em interagir com certas empresas do ramo, revelando um mercado competitivo e de elevado interesse econômico, com expressivo desenvolvimento de tecno- 


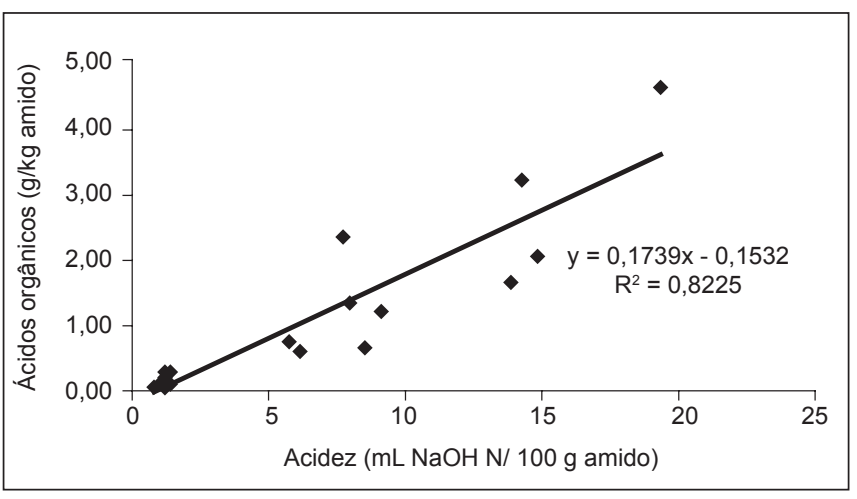

FIGURA 7 - Regressão linear entre os valores de acidez e de ácidos orgânicos das amostras

logia. Foi possível constatar que existe um interesse crescente da indústria alimentícia brasileira nos amidos modificados e também que as empresas que desenvolvem estes ingredientes têm lançado novos produtos no mercado nacional.

As análises de pH, acidez, carboxilas e ácidos orgânicos permitiram concluir que os amidos modificados não foram completamente lavados, havendo presença de restos de reagentes e subprodutos das reações. Após a lavagem das amostras não foi possível correlacionar a acidez com o teor de carboxilas.

Os amidos modificados apresentaram propriedades tecnológicas de interesse a algumas aplicações na indústria de alimentos tais como a resistência de suas pastas a ciclos de congelamento e descongelamento e elevada expansão quando utilizados na produção de biscoitos. As fontes mais utilizadas nas modificações estudadas foram, em ordem decrescente de importância, a mandioca, o milho ceroso e o milho regular.

\section{5 - REFERÊNCIAS BIBLIOGRÁFICAS}

[1] BEMILLER, J.N. Starch modification: challenges and prospects. Starch/Stärke, v. 49, n. 4, p 31-127, 1997.

[2] BOURSIER, B. Applications alimentaires des amidons modifiés. Industries Alimentaires et Agricoles, v. 111, p. 2-11, Septembre 1994.

[3] CEREDA, M.P. Avaliação da qualidade de duas amostras de fécula fermentada de mandioca (polvilho azedo). Boletim da sbCTA, v. 17, n. 3, p. 305-320, 1983a.

[4] CEREDA, M.P. Determinação de viscosidade de fécula fermentada de mandioca (polvilho azedo). Boletim da sbCTA, v. 17. n. 1, p. 15-24, 1.983b.

[5] CEREDA, M.P. Propriedades gerais do amido. São Paulo, Fundação Cargill, 221 p. (Série: Culturas de Tuberosas Amiláceas Latino-americanas, v. 1) 2002.

[6] CEREDA, M.P.; WOSIACKI, G. Characterization of pinhão starch. Part II. Rheological properties of the pastes. Starch/Stärke, v. 37, n. 12, p. 404-407, 1985.

[7] DEMIATE, I.M.; CEREDA, M.P. Some physico-chemical characteristics of modified cassava starches presenting baking property. Energia na Agricultura, v. 15, n. 3, p. 36-46, 2000.

[8] DEMIATE, I.M.; DUPUY, N.; HUVENNE, J.P.; CEREDA, M.P.; WOSIACKI, G. Relationship between baking behavior of modified cassava starches and starch chemical structure determined by FTIR spectroscopy. Carbohydrate Polymers, v. 42, n. 2, 149-158, 2000.

[9] DUPUY, N. Analyse quantitative par spectrométrie moyen infrarouge par transformée de Fourier. Mise au point des protocoles transposables en millieu industriel. Lille. 1993. 120 p. Thèse de doctorat. Université du Droit et de la Santé de Lille.

[10] DUPUY, N. Chimiometrie en spectrometrie infrarouge. Lille. 1997. 90 p. Memoire presenté à l'Université des Sciences et Technologie de Lille pour obtenir l'habilitation a diriger les recherches.

[11] DUPUY, N., WOJCIECHOWSKI, C., TA, C.D., HUVENNE, J.P., LEGRAND, P. Mid-infrared spectroscopy and chemometrics in corn starch classification. Journal of Molecular Structure, v. 410-411, p. 551-554, 1997.

[12] FRINGANT, C.; DESBRIÈRES, J.; RINAUDO, M. Physical properties of acetylated starch-based materials: relation with their molecular characteristics. Polymer, v. 37, n. 13, p. 2.663-2.673, 1996.

[13] GARCIA, V. Transitions thermiques de l'amidon de manioc en millieux peu hydratés. Paris. 1996. Thèse de doctorat. Institut National Agronomique de ParisGrignon.

[14] GUILBOT, A.; MERCIER, C. STARCH. In: The polysaccharides, v. 3, p 209-273, 1985.

[15] HARRICK, N. Internal Reflection Spectroscopy, v. 30, New York, Harrick Scientific Corp. Ossining, 1979.

[16] HWANG, M.P., HAYAKAWA, K-I. Bulk densities of cookies undergoing commercial baking processes. Journal of Food Science, v. 45, p. 1.400-1.402-1.407, 1980.

[17] INTERNATIONAL STARCH INSTITUTE. Determination of reductive power in starch. Disp. in: http://home3. inet.tele.dk/starch/isi/methods/35rcu.htm. Acesso em: 22 jul. 2001.

[18] LEACH, H.W.; McCOWEN, L.D.; SCHOCH, T.J. Structure of the starch granule. I. Swelling and solubility patterns of various starches. Cereal Chemistry, v. 36, n. 6, p. 534-544, 1959.

[19] LEONEL, M.; CEREDA, M.P. Caracterização físico-química de algumas tuberosas amiláceas. Ciência e Tecnologia de Alimentos, v. 22, n. 1, p. 65-69, 2002.

[20] LEONEL, M.; JACKEY, S.; CEREDA, M.P. Processamento industrial de fécula de mandioca e batata doce - um estudo de caso. Ciência e Tecnologia de Alimentos, v. 18, n. 3, p. 343-345, 1998.

[21] MESTRES, C., ROUAU, X. Influence of natural fermentation and drying conditions on the physicochemical characteristics of cassava starch. Journal of the Science of Food and Agriculture, v. 74, p. 147-155, 1997.

[22] SMITH, R.J. Characterization and analysis of starches. In: WHISTLER, R.L., PASCHALL, E.F. Starch: Chemistry and Technology. New York, Academic Press, v. 2, p. 569-635, 1967.

[23] VILPOUX, O. Uso de amidos e aditivos com propriedades em produtos alimentícios. In: II Simpósio Latinoamericano de Raíces y Tubérculos. 28-30 de noviembre, 2001. Universidad Nacional la Molina, Lima, Peru.

[24] WURZBURG, O.B. Modified starches: properties and uses. Boca Raton, CRC Press, 277 p., 1986. 